\title{
Kinetics and Mechanism of 13-Vanadomanganate(IV) Catalyzed Oxidation of Benzoic Acid Hydrazide by Bromatein Buffer Solution of pH 4.0
}

\author{
S. D. KADAM and G. S. GOKAVI* \\ Kinetics and Catalysis Laboratory, Department of Chemistry, \\ Shivaji University Kolhapur 416004, India \\ kadamsanjay123@gmail.com
}

Received 2 February 2016 / Accepted 13 February 2016

\begin{abstract}
Vanadomanganate(IV) catalyzed benzoic acid hydrazide oxidation by bromate was studied in sodium acetate-acetic acid buffer solution of $\mathrm{pH}$ 4.0. The order in oxidant concentration, substrate and catalyst were found to unity.The accelerating effect of hydrogen ion concentration is due to the prior protonation of the substrate. The initiation of the reaction involves the formation of a complex between catalyst and the protonated form of substrate, hydrazide as evidenced by the occurrence of absorption maxima at $390 \mathrm{~nm}$. The complex thus formed is further oxidized by the oxidant in a rate determining step. Benzoic acid was found to be the oxidation product. Other kinetic data like effect of solvent polarity and the activation parameters determined also supports the proposed mechanism.
\end{abstract}

Keywords: Benzoic acid hydrazide, Bromate, Oxidation, Catalysis

\section{Introduction}

Polyoxometalates exhibit attractive properties, which result in intriguing applications ranging from medicine, catalysis to material science. These salts are used ${ }^{1-3}$ as oxidants and catalysts (both redox and acid) for various organic transformations. Most of the electron transfer reactions of POM anions and their mechanistic studies are concentrated on the Keggin type $\mathrm{POM}^{4-7}$ as an oxidant, containing hetero atom in its higher oxidation state. Variety of organic and inorganic substrates has been oxidized by these POMs and the mechanisms generally follow outer sphere pathway. Polyoxometalate contains a hetero atom which is surrounded by number of oxoanions thus making the central hetero atom unavailable for the inner sphere interaction with the substrate. In comparison with Keggin and Dawson type of salts, less attention is given to other type of POM anions. In continuation of our interest ${ }^{8-10}$ in the electron transfer reactions involving POMs, the present study, oxidation of benzoic acid hydrazide (BAH), by bromate catalyzed by 13-vanadomanganate(IV), was carried out in acetic acidsodium acetate buffer solution of $\mathrm{pH}$ 4.0. 
Hydrazides are pharmaceutically important compounds as anti-tubercular ${ }^{11}$ and antibacterial $^{12}$ agent. Hydrazides on oxidation generally give corresponding acids ${ }^{9}$ and in some cases $^{13}$ esters or amides. Hydrazides have also been converted into $N$ - $N$-diacylhydrazines with various oxidants ${ }^{14}$.

The oxidant in present study is potassium bromate, generally product of bromate oxidations is mainly bromide ion which can be safely treated and recycled thus making the method environmentally benign than metal ion oxidation. Also $\mathrm{KBrO}_{3}$ is a strong oxidizing agentwith redox potential $1.45 \mathrm{~V}$, but its rate of oxidation of organic substrates is slow which requires a catalyst ${ }^{15}$ to initiate the reaction, hence in present study the catalyst 13vanadomanganate (IV) was used.

\section{Experimental}

Reagent-grade chemicals and doubly distilled water were used throughout the work. The $\mathrm{KBrO}_{3}$ solution was prepared by dissolving $\mathrm{KBrO}_{3}(\mathrm{BDH})$ in water and standardized iodometrically. The solution of benzoic acid hydrazide (Alfa Aesar) was prepared by dissolving requisite amount of it in water. The catalyst ammonium 13-vanadomanganate(IV) was prepared by the previously reported method ${ }^{16}$ and its solution was prepared by dissolving it in sodium acetate-acetic acid buffer solution. Acetonitrile was used directly as received to study the effect of solvent polarity on the reaction medium.

\section{Kinetic measurements}

The reaction was studied under pseudo-first-order conditions keeping hydrazide concentration large excess at constant temperature of $30.0 \pm 0.1^{\circ} \mathrm{C}$. The reaction was initiated by mixing the previously thermostated solutions of oxidant, catalyst and substrate, which also contained the required amount of acetonitrile, buffer solution and doubly distilled water. The reaction was followed by titrating the reaction mixture for unreacted oxidant iodometrically and the rate constants were determined from the pseudo-first-order plots of $\log$ [oxidant] against time. The pseudo-first-order plots were linear for more than $90 \%$ completion of the reaction and the rate constants were reproducible within $\pm 6 \%$.

\section{Results and Discussion}

\section{Product analysis and stoichiometry}

In $10 \mathrm{~mL}$ acetic acid-sodium acetate buffer solution of $\mathrm{pH} 4.0,32 \mu \mathrm{mol}(5.0 \mathrm{mg})$ catalyst and $1 \mathrm{mmol}(0.136 \mathrm{~g})$ of benzoic acid hydrazide were dissolved. To the resulting solution $1 \mathrm{mmol}(0.167 \mathrm{mg})$ of $\mathrm{KBrO}_{3}$ was added. The reaction mixture was stirred at $30{ }^{\circ} \mathrm{C}$ for five minutes. The benzoic acid separated was filtered and recrystallized by water. The m.p. of the recrystallized product was found to be $121{ }^{\circ} \mathrm{C}$ (lit. m.pt. $121{ }^{\circ} \mathrm{C}$ ). Therefore the stoichiometry of the reaction is found to be two moles of oxidant per three moles of the hydrazide.

\section{Effect of oxidant and hydrazide}

The uncatalysed reaction did not occur under experimental conditions. The catalyzed reaction was carried out under pseudo-first-order conditions keeping the concentration of hydrazide large excess at constant $\mathrm{pH}$ andtemperature (Table 1). The pseudo-first-order plots of $\log \left[\mathrm{BrO}_{3}{ }^{-}\right]$against time were found to be linear and also the values of pseudo-firstorder rate constants were fairly constant as concentration of oxidant and hydrazide were varied (Table 1), indicating order in oxidant and hydrazide to be unity each. 


\section{Effect of catalyst concentration}

The effect of catalyst was studied by varying catalyst concentration in between $5.0 \times 10^{-6}$ to $1.0 \times 10^{-4} \mathrm{~mol} \mathrm{dm}^{-3}$ in sodium acetate-acetic acid buffer solution of $\mathrm{pH} 4.0$. The pseudo-first order rate constants $\left(\mathrm{k}_{\mathrm{obs}}\right)$ for the effect of catalyst concentration obtained from the plots of $\log \left[\mathrm{KBrO}_{3}\right]$ against time (Table 1). The plot of $\mathrm{k}_{\text {obs }}$ against $\left[\left(\mathrm{NH}_{4}\right)_{7}\left[\mathrm{Mn}^{\mathrm{IV}} \mathrm{V}_{13} \mathrm{O}_{38}\right] .5 \mathrm{H}_{2} \mathrm{O}\right]$ was found to be linear indicating the first order dependence of reaction on catalyst.

\section{Effect of $p H$ of medium}

The effect of $\mathrm{pH}$ of medium was studied in order to understand the nature of reactant species present in the solution. The effect of $\mathrm{pH}$ was carried out by varying the $\mathrm{pH}$ of solution from 3.5 to 5.0 by keeping concentrations of hydrazide, potassium bromate, and catalyst constant (Table 1). The rate of reaction is decreases as $\mathrm{pH}$ of solution increases.

\section{Effect of solvent polarity and temperature}

The effect of solvent polarity and temperature were studied by keeping [hydrazide], $\left[\mathrm{KBrO}_{3}\right]$ and [catalyst] constant at $1.0 \times 10^{-2}, 1.0 \times 10^{-3}, 3.0 \times 10^{-5} \mathrm{~mol} \mathrm{dm}^{-3}$ at $\mathrm{pH}=4.0$. Acetonitrile was used to vary solvent polarity of medium. It was found that decrease in dielectric constant of medium increases rate of reaction. The effect of temperature on reaction was studied at 20 , 25,30 and $40{ }^{\circ} \mathrm{C}$ and the pseudo-first-orderrate constants were found to be $3.07 \times 10^{-4}$, $7.29 \times 10^{-4}, 8.83 \times 10^{-4}$ and $36.08 \times 10^{-4} \mathrm{~s}^{-1}$, respectively. The activation parameters $\mathrm{E}_{\mathrm{a}}, \Delta \mathrm{H}^{\#}, \Delta \mathrm{G}^{\#}$ and $-\Delta \mathrm{S}^{\#}$ were found to $90.06 \pm 5 \mathrm{~kJ} \mathrm{~mol}^{-1}, 88.10 \pm 6 \mathrm{~kJ} \mathrm{~mol}^{-1}, 91.39 \pm 7 \mathrm{~kJ} \mathrm{~mol}^{-1}$ and $10.896 \pm 1$ $\mathrm{Jk}^{-1} \mathrm{~mol}^{-1}$ respectively.

Table 1. Effect of $[\mathrm{BAH}],\left[\mathrm{KBrO}_{3}\right],[$ Catalyst $]$ and $\mathrm{pH}$ on the rate of reaction at $30^{\circ} \mathrm{C}$

\begin{tabular}{ccccc}
\hline $\begin{array}{c}10^{2}[\mathrm{BAH}] \\
\mathrm{mol} \mathrm{dm}^{-3}\end{array}$ & $\begin{array}{c}10^{3}\left[\mathrm{KBrO}_{3}\right] \\
\mathrm{mol} \mathrm{dm}^{-3}\end{array}$ & $\begin{array}{c}10^{5}[\mathrm{Catalyst}] \\
\mathrm{mol} \mathrm{dm}^{-3}\end{array}$ & $\mathrm{pH}$ & $10^{4} \mathrm{k}_{\mathrm{obs}} \mathrm{s}^{-1}$ \\
\hline 0.5 & 1.0 & 3.0 & 4.0 & 7.70 \\
0.75 & 1.0 & 3.0 & 4.0 & 7.68 \\
1.0 & 1.0 & 3.0 & 4.0 & 7.68 \\
2.5 & 1.0 & 3.0 & 4.0 & 7.68 \\
5.0 & 1.0 & 3.0 & 4.0 & 7.69 \\
1.0 & 0.4 & 3.0 & 4.0 & 7.70 \\
1.0 & 0.8 & 3.0 & 4.0 & 7.70 \\
1.0 & 1.0 & 3.0 & 4.0 & 7.70 \\
1.0 & 2.0 & 3.0 & 4.0 & 7.70 \\
1.0 & 4.0 & 3.0 & 4.0 & 7.68 \\
1.0 & 1.0 & 0.5 & 4.0 & 1.54 \\
1.0 & 1.0 & 0.8 & 4.0 & 2.30 \\
1.0 & 1.0 & 1.0 & 4.0 & 3.45 \\
1.0 & 1.0 & 3.0 & 4.0 & 7.68 \\
1.0 & 1.0 & 5.0 & 4.0 & 10.36 \\
1.0 & 1.0 & 7.0 & 4.0 & 13.43 \\
1.0 & 1.0 & 10.0 & 4.0 & 20.34 \\
1.0 & 1.0 & 3.0 & 3.5 & 26.5 \\
1.0 & 1.0 & 3.0 & 4.0 & 7.68 \\
1.0 & 1.0 & 3.0 & 4.5 & 3.70 \\
1.0 & 1.0 & 3.0 & 5.0 & 0.84 \\
\hline
\end{tabular}


The catalyst $\left[\mathrm{Mn}^{\mathrm{IV}} \mathrm{V}_{13} \mathrm{O}_{38}\right]^{7-}$ used in the present study has two redox centers $\mathrm{Mn}^{\text {IV }}$ within the vanadium polyoxometalate cage and $\mathrm{V}^{\mathrm{V}}$ as the addenda ion. The reduction of both the ions is possible in presence of a strong reductant ${ }^{17}$. Reduction of $\mathrm{Mn}^{\mathrm{IV}}$ center results after the reduction of all the thirteen $\mathrm{V}^{\mathrm{V}}$ since it is buried within the polyoxometalate structure. It has also been proposed that after the reduction of all the $\mathrm{V}^{\mathrm{V}}$ ions in the outer cage the polyoxometalate structure will be totally dismantled thus making possible the interaction between the $\mathrm{Mn}^{\mathrm{IV}}$ and the reductant. During such reduction of both the hetero atom $\left(\mathrm{Mn}^{\mathrm{IV}}\right)$ and the addenda atom $\left(\mathrm{V}^{\mathrm{V}}\right)$, formation of a heteropoly blue is expected ${ }^{17}$. In order to understand the type of interaction between the catalyst and the hydrazides the spectrophotometric examination of a mixture of catalyst and the hydrazide was examined. The spectra obtained as function of time and after the addition of $\mathrm{KBrO}_{3}$ into such a mixture were shown in Figure 1. It can be noticed from the figure that the after addition of benzoic acid hydrazide a peak around $390 \mathrm{~nm}$ is obtained and its intensity increases with time even after a day. To such a mixture when oxidant, $\mathrm{KBrO}_{3}$ is added the intensity at $390 \mathrm{~nm}$ decreases immediately. This observation indicates that there is a complex formation between benzoic acid hydrazide and the catalyst which further undergo oxidation when the bromate is added. Such type of complex formation is also noticed earlier by our group ${ }^{14}$. In a recent study during oxidation of 2-mercaptoethanol by $\left[\mathrm{Mn}^{\mathrm{IV}} \mathrm{V}_{13} \mathrm{O}_{38}\right]^{7-}$ ion ${ }^{17}$ formation of heteropoly blue due to the reduction of $\mathrm{V}^{\mathrm{V}}$ with an absorption peak at $685 \mathrm{~nm}$ is observed. Therefore, if the heteropolyblue is formed an absorption peak at $685 \mathrm{~nm}$ is expected. As in the present study the characteristic peak of heteropoly blue is absent but a different peak at $390 \mathrm{~nm}$ is observed (Figure 1) with increase in intensity as the time increases. Further the intensity of the peak decreases when the oxidant, $\mathrm{KBrO}_{3}$ is added. This indicates that there is prior complex formation between the catalyst and the hydrazide which undergo oxidation in presence of oxidant. Therefore, reaction was initiated by the complex formation between the catalyst and hydrazide followed by its oxidation by oxidant in a rate determining step. The test for formation of bromide ion was carried out in sulphuric acid solution instead of hydrochloric acid by adding silver nitrate to the reaction mixture after completion of the reaction. The precipitation of silver bromide confirms the formation of bromide as one of the product of the reaction. Therefore, the product of the reaction under the experimental conditions is bromide ion. It is also noticed during the kinetic studies and the stoichiometric analysis that no bromine was evolved, further confirming the bromide ion as the only product. The accelerating effect of hydrogen ion concentration on the reaction with an order of unity in its concentration is due to the various protonation equilibria of the oxidant and the catalyst. The first protonation constant of $\left[\mathrm{Mn}^{\mathrm{NV}} \mathrm{V}_{13} \mathrm{O}_{38}\right]^{7-}$ is generally high ${ }^{17}$ the anion is in the protonated form below the $\mathrm{pH}=5$. Therefore, since the present study was carried out between the $\mathrm{pH}$ range 3.5 to 5.0 the catalyst $\left[\mathrm{Mn}^{\mathrm{IV}} \mathrm{V}_{13} \mathrm{O}_{38}\right]^{7-}$ will be in its protonated form. Potassium bromate is a strong electrolyte and in aqueous solution it exists as $\mathrm{BrO}_{3}{ }^{-}$which is also a strong acid thus its protonation would not be possible under the experimental conditions. Another possibility that $\left[\mathrm{H}^{+}\right]$ion dependence may be due to involvement of an induction period $^{18}$, as observed in bromate oxidations, is also ruled out as no such induction period was observed. Therefore, the accelerating effect of hydrogen ion concentration is due to the prior protonation of the substrate, hydrazides. Hydrazides are known to undergo protonation ${ }^{14}$ in acid, and both protonated and unprotonated species exit in such solution to different extent. The order in both oxidant and reductant were found to be unity whereas, the order in catalyst concentration was also found to be unity Therefore, the initiation of the reaction is the formation of a complex between catalyst and the protonated form hydrazide in prior equilibria. Since, the reactions did not follow Michaelis-Menten type of kinetics 
as the rate constants remain constant as the concentration in of hydrazides increased, the formation of complex occurs rapidly. The complex thus formed is further oxidized by the oxidant in a rate determining step as shown in Scheme 1.

$$
\begin{aligned}
& \mathrm{RCONHNH}_{2}+\mathrm{H}^{+} \stackrel{\mathrm{KH}}{\rightleftharpoons} \mathrm{RCONHNH}_{3}{ }^{+} \\
& \mathrm{H}\left[\mathrm{Mn}^{\mathrm{N} V} \mathrm{~V}_{13} \mathrm{O}_{38}\right]^{6-}+\mathrm{RCONHNH}_{3}{ }^{+} \stackrel{\mathrm{K}_{\mathrm{c}}}{\longrightarrow} \text { Complex } \\
& \text { Complex } \left.+\mathrm{BrO}_{3}{ }^{-}\right] \stackrel{\mathrm{k}_{1}}{\longrightarrow} \mathrm{H}\left[\mathrm{Mn}^{\mathrm{N}} \mathrm{V}_{13} \mathrm{O}_{38}\right]^{6-}+\mathrm{BrO}_{2}+\mathrm{RCONHNH}+\mathrm{H}_{2} \mathrm{O} \\
& \mathrm{RCONHNH}+\mathrm{H}_{2} \mathrm{O}+\mathrm{H}^{+} \stackrel{\text { Fast }}{\longrightarrow} \mathrm{RCOOH}+\mathrm{NHNH}_{2} \\
& \begin{array}{lll}
\mathrm{BrO}_{2}+\mathrm{NHNH}_{2} & \stackrel{\text { Fast }}{\longrightarrow} & \mathrm{HBrO}_{2}+\mathrm{NHNH} \\
\mathrm{N}=\mathrm{NH}+\mathrm{HBrO}_{2} & \text { Fast } & \mathrm{N}_{2}+2 \mathrm{H}_{2} \mathrm{O}+\mathrm{HOBr}
\end{array} \\
& 2 \mathrm{HOBr}+2 \mathrm{HN}=\mathrm{NH} \stackrel{\text { Fast }}{\longrightarrow} 2 \mathrm{~N}_{2}+4 \mathrm{H}_{2} \mathrm{O}+2 \mathrm{H}^{+} 2 \mathrm{Br}^{-}
\end{aligned}
$$

\section{Scheme 1}

The rate law according to Scheme 1 can be derived as follows. The rate of reaction is given by,

$$
\begin{aligned}
\text { Rate } & =\mathrm{k}_{1}[\text { Complex }]\left[\mathrm{BrO}_{3}^{-}\right] \\
& =\mathrm{k}_{1} \mathrm{~K}_{\mathrm{c}} \mathrm{H}\left[\mathrm{Mn}^{\mathrm{IV}} \mathrm{V}_{13} \mathrm{O}_{38}\right]^{6-}\left[\mathrm{RCONHNH}_{3}{ }^{+}\right]\left[\mathrm{BrO}_{3}^{-}\right]
\end{aligned}
$$

Substituting for $\left[\mathrm{RCONHNH}_{3}{ }^{+}\right]$from equilibrium 1 of scheme 1 ,

$$
\begin{aligned}
& \text { Rate }=\frac{\mathrm{k}_{1} \mathrm{~K}_{\mathrm{c}} \mathrm{H}\left[\mathrm{Mn}^{\mathrm{IV}} \mathrm{V}_{13} \mathrm{O}_{38}\right]^{6-}\left[\mathrm{RCONHNH}_{3}^{+}\right]\left[\mathrm{BrO}_{3}^{-}\right]}{\left(1+\mathrm{K}_{\mathrm{H}}\left[\mathrm{H}^{+}\right]\right)} \\
& \mathrm{k}_{\mathrm{obs}}=\frac{\mathrm{k}_{1} \mathrm{~K}_{\mathrm{c}} \mathrm{H}\left[\mathrm{Mn}^{\mathrm{IV}} \mathrm{V}_{13} \mathrm{O}_{38}\right]^{6-}\left[\mathrm{RCONHNH}_{3}^{+}\right]\left[\mathrm{BrO}_{3}^{-}\right]}{\left(1+\mathrm{K}_{\mathrm{H}}\left[\mathrm{H}^{+}\right]\right)}
\end{aligned}
$$

In Scheme 1 formation of hydrazide-free radicals was considered and such free radicals have been predicted in oxidations of hydrazide by one-electron oxidizing agents ${ }^{14,19}$. In one such study on oxidation of amino benzohydrazide by hydrogen peroxide mediated by myeloperoxidase $^{18}$, a ferric enzyme, it has been observed that the hydrazide-free radical produced also undergo slow oxidation by the dissolved oxygen. Therefore, the reaction was carried out in nitrogen atmosphere to know the effect of dissolved oxygen. It was found that there was no change in the pseudo first-order rate constant when the reaction was carried out in nitrogen atmosphere indicating no effect of the dissolved oxygen on the reaction. The stoichiometric analysis of the reaction mixture led to benzoic acid as the major product. The formation of benzoic acid in the present reaction can be explained due to the nucleophilic attack on the carbonyl carbon of the hydrazide free radical by water molecule simultaneously generating the catalyst back. Further oxidation leads to the formation of 
$\mathrm{NHNH}_{2}$ free radical. The $\cdot \mathrm{NHNH}_{2}$ free radical produced preferably reacts with strong one-electron oxidant $\mathrm{BrO}_{2}$ generated in the slow step of Scheme 1, leading to the formation of $\mathrm{HBrO}_{2}$ and $\mathrm{NHNH}$. The final product nitrogen is formed as a result of fast reactions of $\mathrm{NHNH}$ with intermediates of bromate, $\mathrm{HBrO}_{2}$ and $\mathrm{HOBr}$ as shown in Scheme 1 . The probable structure of the complex between the oxidized form of the catalyst and the hydrazide can be coordination of hydrazide ligand through oxygen and nitrogen atoms to the $\mathrm{V}^{\mathrm{V}}$. The moderate values of $\Delta \mathrm{H}^{\#}$ and $\Delta \mathrm{S}^{\#}$ were both favorable ${ }^{20}$ for electron transfer processes. The negative value of $\Delta S^{\#}$, within the range for free radical reactions ${ }^{21}$, has been ascribed to the nature of electron pairing and unpairing processes and to the loss of degrees of freedom formerly available to the reactants upon the formation of rigid transition state.

\section{Conclusion}

The reaction between benzoic acid hydrazide and $\mathrm{KBrO}_{3}$ in presence of 13-vanadomanganate(IV) as a catalyst occurs through formation of a complex between catalyst and hydrazide which will be oxidized by oxidant in rate determining step. The mechanism proposed on the basis of kinetic data and benzoic acid is the product of reaction. In present study the protonated from of the hydrazide as well as catalyst is active species. The probable transition state was considered to be interaction between oxygen and nitrogen of the hydrazide moiety with the oxidized from of the catalyst leading to the formation of complexwith absorption maxima at $390 \mathrm{~nm}$.

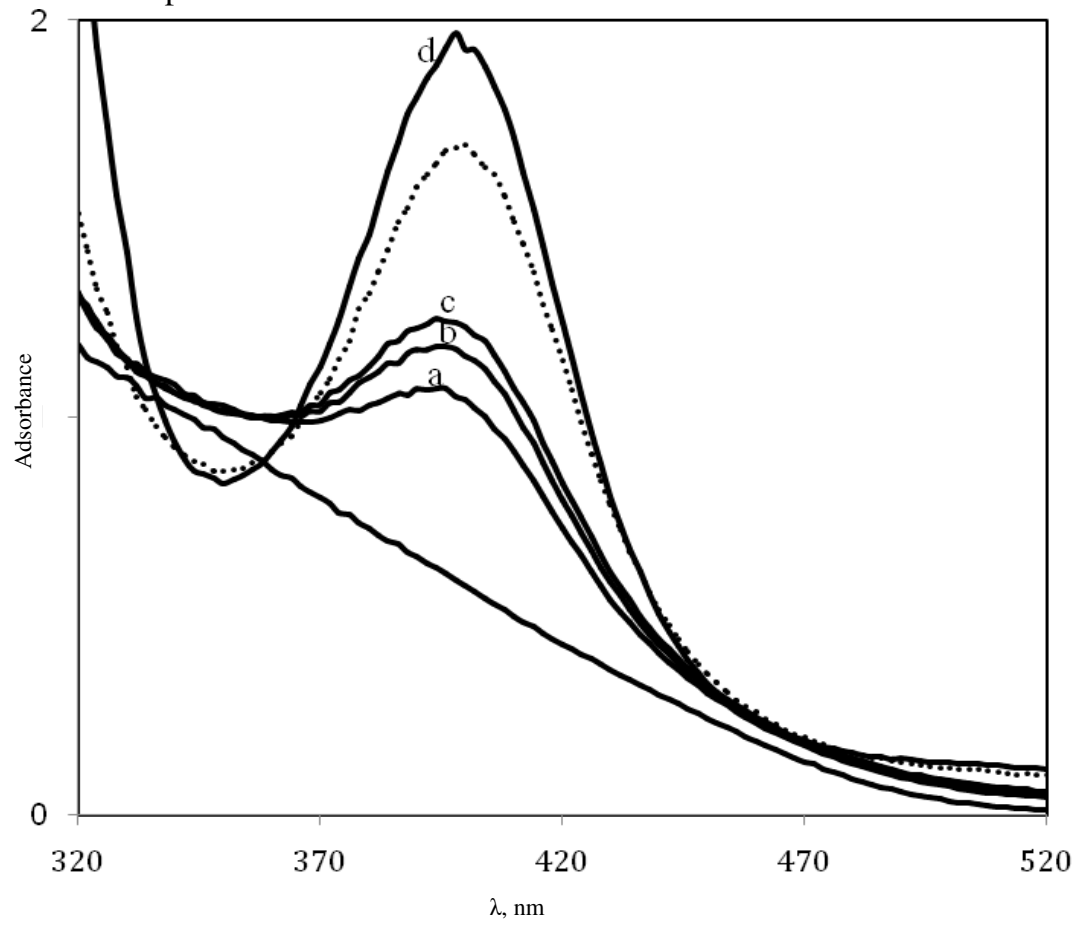

Figure 1. UV-Vis spectrophotometric examination of the mixture containing catalyst and benzoic acid hydrazide (dashed line - pure $\left[\mathrm{Mn}^{\mathrm{IV}} \mathrm{V}_{13} \mathrm{O}_{38}\right]^{7-}, \mathrm{a}, \mathrm{b}, \mathrm{c}, \mathrm{d}$ are spectra after 2, 10 , 15 and one day of the reaction mixture and dotted line - spectra after addition of $\mathrm{KBrO}_{3}$ ) $10^{4}\left[\mathrm{Mn}^{\mathrm{IV}} \mathrm{V}_{13} \mathrm{O}_{38}\right]^{7-}=1.0 \mathrm{~mol} \mathrm{dm}{ }^{-3} 10^{4}[\mathrm{BAH}]=1.0 \mathrm{~mol} \mathrm{dm}^{-3} \mathrm{pH}=4.0$ at $30^{\circ} \mathrm{C}$ 


\section{References}

1. Sadakane $\mathrm{M}$ and Steckhan E, Chem Rev., 1998, 98(1), 219-238; DOI:10.1021/cr960403a

2. Katsoulis D E, Chem Rev., 1998, 98(1), 359-388; DOI:10.1021/cr960398a

3. Weinstock I A, Chem Rev., 1998, 98(1), 113-170; DOI:10.1021/cr9703414

4. Ayoko G A, Transition Met Chem., 1990, 15(6), 421-424; DOI:10.1007/BF01040768

5. Hasure A M and Gokavi G S, Reaction Kinet Cat Lett., 2003, 80(1), 59-65; DOI:10.1023/A:1026024007436

6. Saha S K, Ghosh M C and Banerjee P, Int J Chem Kinet., 1988, 20(9), 699-712; DOI:10.1002/kin.550200904

7. Mehrotra M and Mehrotra R N, J Chem Soc., Dalton Trans., 2003, 3606-3611; DOI:10.1039/B304123A

8. Bhosale B D and Gokavi G S, Indian J Chem., 2006, 45A, 398-401.

9. Kadam S D, Supale A R and Gokavi G S, Trans Met Chem., 2008, 33(8), 989-994; DOI:10.1007/s11243-008-9141-4

10. Kadam S D, Supale A R and Gokavi G S, Z Phys Chem., 2008, 222(4), 635-646; DOI:10.1524/zpch.2008.5289

11. Werner W, J Org Chem., 1953, 18(10), 1333-1337; DOI:10.1021/jo50016a011

12. Winterstein A, Hegedus H, Fust B, Bohni E and Studer A, Helv Chim Acta, 1956, 39(1), 229-248; DOI:10.1002/hlca.19560390127

13. Hoffman R V and Kumar A, J Org Chem., 1984, 49(21), 4011-4014; DOI:10.1021/jo00195a027

14. Shewale S A, Phadkule A N and Gokavi G S, Int J Chem Kinet., 2008, 40(3), 151159; DOI:10.1002/kin.20296

15. Reddy C S and Kumar T V, Trans Met Chem., 2007, 32(2), 246-256;

DOI:10.1007/s11243-006-0156-4

16. Flynn C M Jr and Pope M T, J Am Chem Soc., 1970, 92(1), 85-90;

DOI:10.1021/ja00704a014

17. Chakrabarty S and Banerjee R, Int J Chem Kinet., 2015, 47(1), 13-18;

DOI:10.1002/kin.20887

18. Mohammad A, Trans Met Chem., 2003, 28(3), 345-349;

DOI:10.1023/A:1022998824875

19. Babshet R M and Gokavi G S, Int J Chem Kinetics, 2002, 34(10), 589-594;DOI: 10.1002/kin. 10088

20. Schnyder J and Rttenberg M, Helv Chim Acta, 1975, 58(2), 521-523;

DOI:10.1002/hlca.19750580222

21. Walling C, Free Radical in Solutions; Academic Press, New York, 1957, p.38 